\title{
Rockfall Hazard Alarm Strategy Based on FBG Smart Passive Net Structure
}

\author{
Sheng $\mathrm{LI}^{1^{*}}$, Junjie $\mathrm{MA}^{2}$, and Jun $\mathrm{HU}^{3}$ \\ ${ }^{1}$ National Engineering Laboratory for Fiber Optic Sensing Technology, Wuhan University of Technology, Wuhan, \\ 430070, China \\ ${ }^{2}$ Wuhan WUTOS Limited Company, Wuhan, 430223, China \\ ${ }^{3}$ Key Laboratory of Fiber Optic Sensing Technology and Information Processing, Ministry of Education, Wuhan \\ University of Technology, Wuhan, 430070, China \\ *Corresponding author: Sheng LI_ E-mail: lisheng@whut.edu.cn
}

\begin{abstract}
In order to realize working state remote monitoring for a passive net, alarm timely and correctly for the rockfall invasion, and solve the disadvantages in the existing means, such as needing power supply in situ, vulnerability to electromagnetic interference and environmental climate impact, a smart passive net structure based on the optical fiber sensing technology was designed which equipped with intercepting and sensing functions. The wire rope net as one part of the smart passive net was weaved with two kinds of optical fiber sensing elements, namely, fiber Bragg grating (FBG) perimeter severity sensors and optical fiber monitoring net with each end of the tail fiber containing an FBG probe. Based on the proposed smart structure, a combination alarm strategy for rockfall was proposed, which can distinguish transmission bug, whether the rockfall invasion or net broken occurs. Through a designed simulation test, the effectiveness of the proposed alarm strategy was certificated.
\end{abstract}

Keywords: Passive net, rockfall hazard, fiber Bragg grating, disaster alarm strategy, tunnel portal

Citation: Sheng LI, Junjie MA, and Jun HU, "Rockfall Hazard Alarm Strategy Based on FBG Smart Passive Net Structure," Photonic Sensors, 2015, 5(1): 19-23.

\section{Introduction}

Due to the rapid development of the railway technology in China in this decade, the operation mileage becomes longer, and the operation speed becomes faster. In order to adapt the improved operation security demand, the study on the geological disasters automatic monitoring and alarming technology for the railway safety operation has been widely carried out. Some provisions $[1,2]$ have clearly pointed out that the passenger railway line should establish the disaster prevention safety monitoring system, monitoring the natural disasters and making sure the security operation of the train. Rockfall [3] is a common disaster in the railway slope structure. Especially, rockfall hazard has a great influence on the operation train through the tunnel portal. Therefore, monitoring and alarming for the rockfall invasion have become the current research hotspots in railway engineering departments. At present, so many studies and applications have been carried out in this field in China and abroad. However, electric-based means which mainly contain the dual power net, microwave, infrared, radar and so on [4-6] all have

Received: 9 June 2014 / Revised version: 4 September 2014

(C) The Author(s) 2014. This article is published with open access at Springerlink.com

DOI: $10.1007 / \mathrm{s} 13320-014-0203-2$

Article type: Regular 
several common disadvantages such as the vulnerability to electromagnetic interference, bad resistance to thunder strike, low reliability of signal long distance transmission, needing power supply in situ, high cost for maintenance and high rate of false alarm. The method based on the video image $[7,8]$ is straightforward but vulnerable to the effects of the bad weather. In order to solve the above existing problems, based on the optical the fiber sensing technology, combined with the rockfall interceptor commonly used in the slope flexible protection systems, a smart passive net structure was designed, and a rockfall alarm strategy based on two types of sensing indicators which can be perceived by the designed FBG(fiber Bragg grating)-based smart passive net was proposed.

\section{Rockfall hazard for the passive net}

\subsection{Passive net structure}

The function of the slope flexible protection system [9] which mainly depends on the wire rope net is to prevent and control the slope rockfall hazard. Covering the potential hazard slope area and intercepting collapse rockfall by the wire rope net are two major working ways for the flexible protection system. As shown in Fig. 1, the intercepting rockfall usually adopts the passive net structure, which is composed of the anchor rod, post, anchor rope, wire rope net and so on. The mesh net structure can play a role for intercepting rockfall when installed in the area at a certain angle of interest [10].

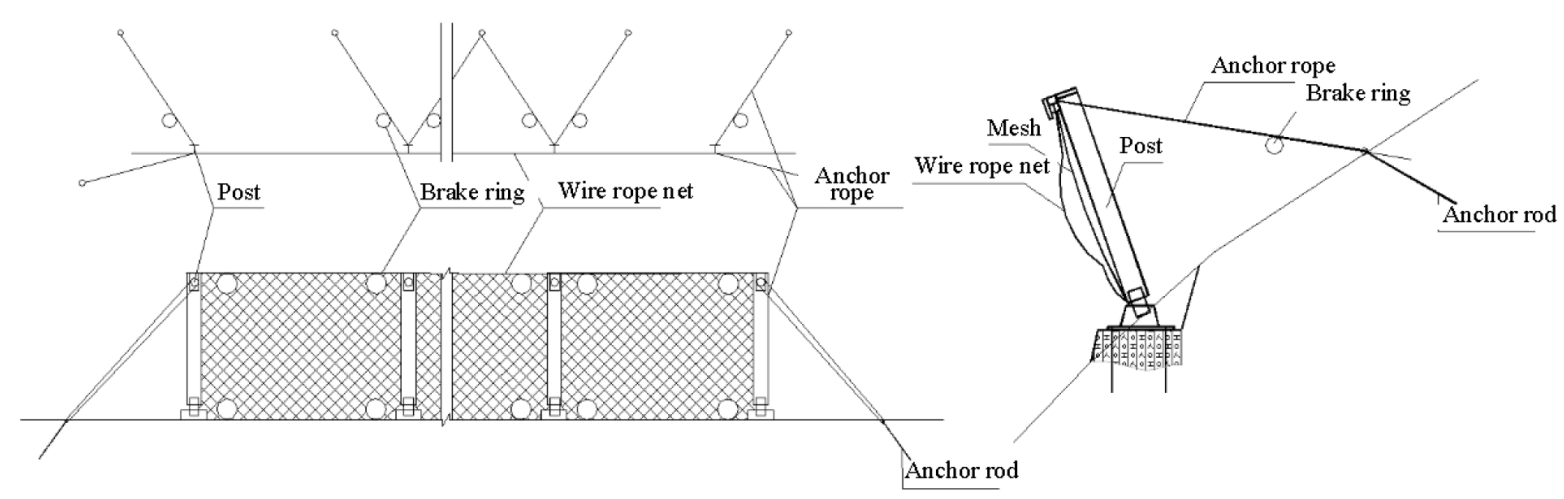

Fig. 1 Structural components of the passive net.

\subsection{Main hazard result analysis}

Assuming that the falling scope of rockfall is not beyond the passive net interception are a, the rockfall impact energy decided by the rock volume, mass, initial falling velocity, and height acting on the absorption energy passive net will lead to the following two hazard results:

(1) When the rockfall impact energy is smaller than the protection energy of the passive net, the rockfall will be blocked by the passive net.

(2) When the rockfall impact energy is larger than the protection energy of the passive net, the passive net will be broken by the rockfall.

In view of the situation (1), the treatment measures contain cleaning the rockfall intercepted by the passive net, checking the state of the passive net, and estimating whether the passive net need to be replaced or repaired. In view of the situation (2), the treatment measures contain cleaning the rockfall that blocks the train operation routes and repairing the passive net. In order to timely dispose the above two kinds of disaster results, it is necessary to monitor the rockfall intercepting state of the passive net and to send alert for rockfall invasion or breaking of the wire rope net.

\section{Rockfall hazard alarm strategy}

\subsection{Strategy implementation basis}

According to the above hazard classification 
results, in order to realize the passive net state intelligent recognition, as shown in Fig. 2, a smart passive net structure was designed, in which the wire rope net was weaved with an FBG perimeter security sensor [11] and an optical fiber monitoring net with both ends of the tail fiber containing FBG probes [12]. The sensing and transmission parts of the designed smart structure as the alarm strategy implementation basis mainly contain the FBG sensors, optical cable, and splice closure. Due to optical signal transmission, there is no need for power supply in situ, and all the monitoring alarm instruments can be placed in the remote gathering station far away from the site through the connection of the optical cable.

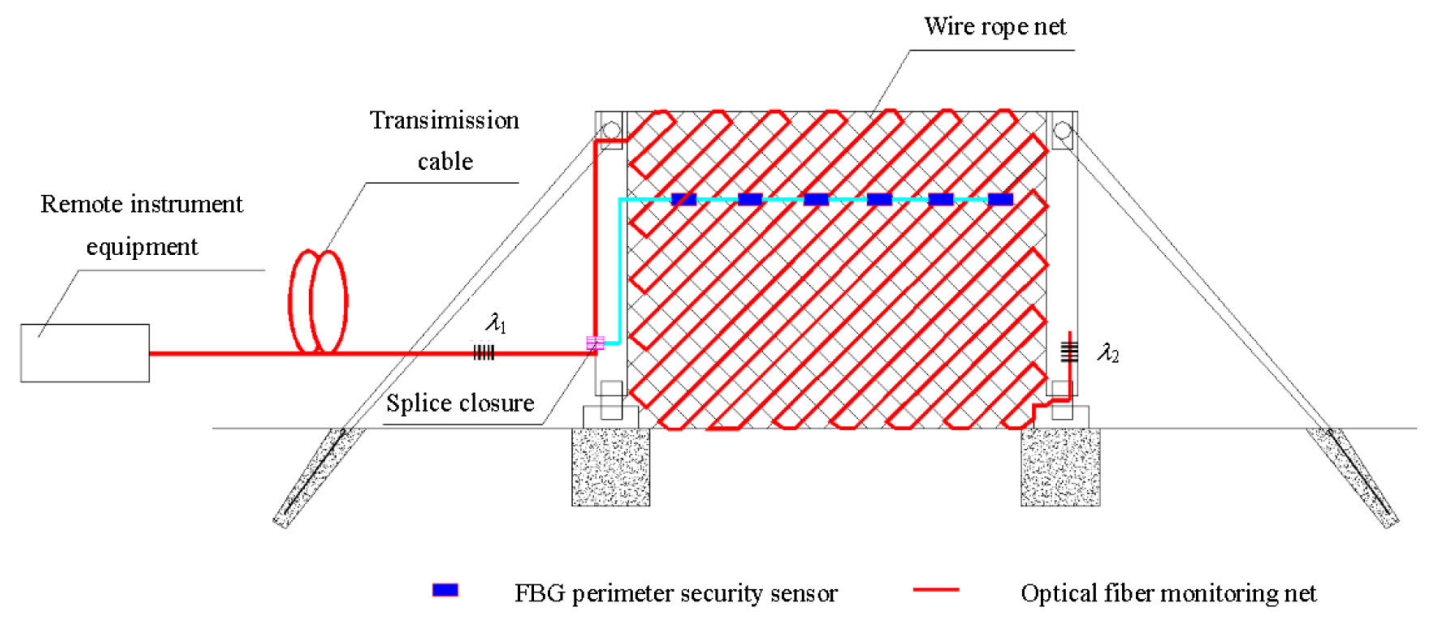

Fig. 2 Smart passive net structure.

The FBG perimeter security sensor structure [13, 14] which has considered the effects of the sensor natural frequency and sensitivity coefficient mainly impacted by different structure sizes and packaging materials is shown in Fig. 3. A pre-tension FBG for improving the sensing sensitivity is fixed at both ends of the protective steel tube. Keeping a proper distance with the FBG probe, a mass block used for tuning the vibration frequency and sensitivity is fixed in the middle of the optical fiber by the epoxy resin adhesive. When rockfall invasion occurs, the mass block inside the sensor and the passive net will vibrate simultaneously, and the wavelength of the FBG probe will drift away from its initial position. In view of the environment in situ, according to the simulation and observation, some typical modes such as animal climbing, breeze and gravel effects which are not elicited by rockfall hazard can be eliminated by establishing a proper alarming threshold. Therefore, based on the established wavelength change threshold, the alarming response for rockfall invasion can be realized.

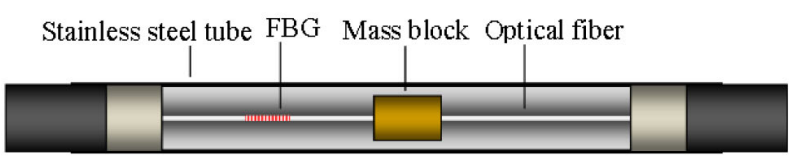

Fig. 3 FBG perimeter security sensor structure.

Besides the FBG perimeter security sensor, an optical fiber monitoring net with each end of the tail fiber containing an FBG probe is weaved together with the wire rope net as another part of the designed smart passive net structure. Because the material strength of the optical cable without the shield is lower than that of the steel wire rope, the optical fiber monitoring net will be destroyed at the same time when the wire rope net is broken due to the rockfall. By using the remote monitoring, based on the on-off state of the tail fiber FBG sensors linked to the optical fiber monitoring net, whether the wire rope net is broken by invaded rockfall can be preliminarily judged. 


\subsection{Combination alarm strategy}

The alarm target for the proposed smart passive net is to forecast whether rockfall invasion or net broken occurs. As shown in Fig. 2, the means that each end of the tail fiber of the optical fiber monitoring net contains an FBG probe with a different wavelength in whick one end is concatenated to the transmission cable can realize the self diagnosis and reduce the false alarm rate for the alarming system. Corresponding to different system statuses, the signal modes of FBG probes connected with the optical fiber monitoring net are shown in Fig. 4. When the passive net structure is in good condition and the system runs properly, two wavelength signals, namely, $\lambda_{1}$ and $\lambda_{2}$, will be received by the remote light signal processor as represented in Fig.4(a). When only $\lambda_{1}$ is received as represented in Fig. 4(b), according to the observation of the vibration response of the FBG perimeter security sensor at the same time, the judgment about whether the wire rope net is broken by rockfall can be made. That both signals of $\lambda_{1}$ and $\lambda_{2}$ vanish as represented in Fig. 4(c) suggests that the transmission cable has some faults needing to be processed. Moreover, due to the reason that the proposed smart passive net is sensitive to two FBG-based sensing indexes, namely, the vibration respond and the working condition of the wire rope net, a combination alarm strategy for rockfall is proposed in Table 1, which considers the logical relationship between the response results and the two kinds of sensors used in the smart passive net. To some extent, the combination strategy can be seen as a way to improve the alarming accuracy by
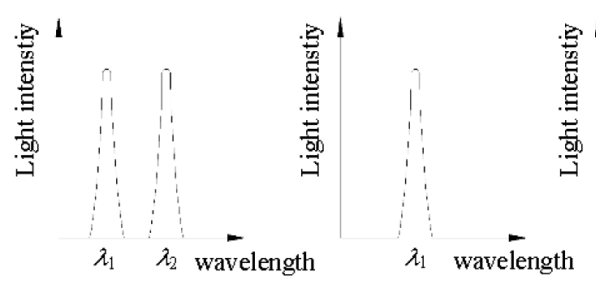

wavelength

(a) Normal

(b) Net broken

(c) Transmission bug

Fig. 4 Probe signal models of the fiber optic monitoring net under different system statuses. adopting the multiplication principle from the statistical theory.

Table 1 Combination alarm monitoring strategy for rockfall.

\begin{tabular}{|c|c|c|c|}
\hline \multicolumn{2}{|c|}{ Sensing response } & \multirow{2}{*}{ Passive net state } & \multirow{2}{*}{ System decision } \\
\hline I & II & & \\
\hline$x$ & $x$ & normal & normal \\
\hline$\sqrt{ }$ & $\sqrt{ }$ & net broken & alarm \\
\hline$\sqrt{ }$ & $\times$ & $\begin{array}{l}\text { rockfall invasion } \\
\text { but net intact }\end{array}$ & $\begin{array}{c}\text { video or } \\
\text { manual review }\end{array}$ \\
\hline$x$ & $\sqrt{ }$ & $\begin{array}{l}\text { interference aroused } \\
\text { by man or data noise }\end{array}$ & self diagnosis \\
\hline
\end{tabular}

Note: "I" and "II" represent the FBG perimeter security sensor and optical fiber monitoring net, respectively. " $\sqrt{ }$ " and " $\times$ " represent whether there is a sensing response or not, respectively.

\subsection{Simulation test}

As shown in Fig. 5, a wire rope net model weaved by $\Phi 3-\mathrm{mm}$ steel and $1 \mathrm{~m} \times 1.5 \mathrm{~m}$ area was used to simulate the critical intercepting part of the proposed smart passive net structure. $\Phi 2 \mathrm{~mm}$ single core cable with each end of tail fiber containing an FBG probe with different wavelengths wrapped around the model net surface to simulate the optical fiber monitoring net. In addition, a string of FBG perimeter security sensors were decorated in the center of the simulated net to glean the vibration signal.

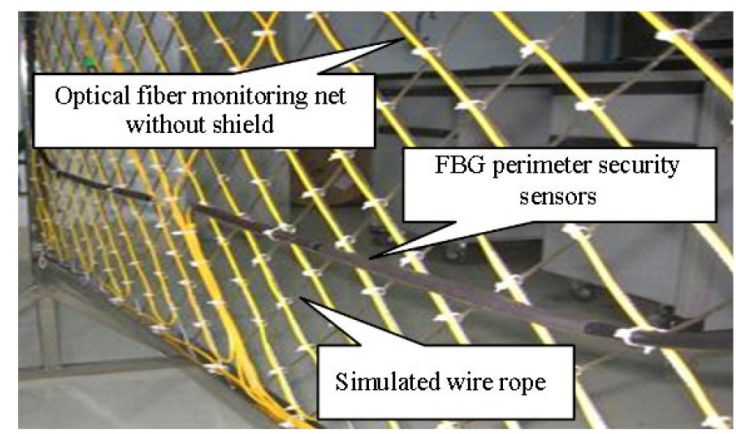

Fig. 5 Simulation test object structure.

According to the combination alarm strategy, the simulated test contents mainly include:

(1) There is a vibration response, but no net broken response.

(2) There is a net broken response, but no vibration response.

(3) Both vibration and net broken responses occur.

In the test, knocking the net model by human was used to simulate the rockfall impact. And 
several optical fiber flanges were added in the light path to simulate the on-off state for the transmission bug and the net breaking of the optical fiber monitoring net. The test results based on the simulated net model show that the way proposed in this paper has a good alarm response and can distinguish several passive net stateses due to the rockfall impact and transmission bug.

\section{Conclusions}

A smart passive net structure equipped with intercepting and sensing functions was designed. Based on the designed structure, a rockfall hazard combination alarm strategy which also considerd system self diagnosis was proposed and verified by a simplified simulation test. Due to the use of the fiber optical sensing technology, the research content has several technique advantages, such as the high reliability for long distance signal transmission, no need for power supply in situ, low rate of false alarm and can be seen as a research reference for establishing the rockfall alarm system in the mountain railway tunnel portal.

\section{Acknowledgment}

The research work reported in this paper was supported by the National Engineering Laboratory for Fiber Optic Sensing Technology, Wuhan University of Technology, China. Thanks for the support of the Fundamental Research Funds for the Central Universities (WUT: 2014-IV-090) and the National Natural Science Foundation of China (Major Program: 61290310).

Open Access This article is distributed under the terms of the Creative Commons Attribution License which permits any use, distribution, and reproduction in any medium, provided the original author(s) and source are credited.

\section{References}

[1] Tie Jian She, Design interim provisions for the newly-built passenger railway line with 300-350 $\mathrm{km} / \mathrm{h}$ speed. Beijing: China Railway Publishing House, 2008, No. 147.

[2] Yun Ji Ji Chu, Disaster prevention safety monitoring system of high speed railway-foreign invasion monitoring scheme for road across railway overpass. Beijing: China Railway Publishing House, 2010: 739.

[3] S. Lambert and F. Bourrier, "Design of rockfall protection embankments: a review," Engineering Geology, 2013, 154(2): 77-88.

[4] T. Wang, H. Shi, Q. Wang, and H. Wang, "Research on instrusion monitoring system for PDL," Railway Computer Application, 2009, 18(7): 8-10.

[5] G. Meng and R. Zheng, "Research on metro gauge inspection system based on laser-photogrammertric method," Journal of Lanzhou Jiaotong University, 2013, 32(4): 5-9.

[6] S. Yin, B. Zhou, and C. Zhang, "Application of infrared imaging to monitor systems for driving safety in railways," Journal of Southwest Jiaotong University, 1997, 32(5): 540-545.

[7] Z. Wang and C. Yang, "Current status and development trend of monitoring systems for expressway tunnels," Modern Tunneling Technology, 2009, 46(6): 8-14.

[8] S. Zhong and Y. Huang, "Application and function discussion on long-term video monitoring system for railway," Chinese Railway, 2008, (5): 45-47.

[9] Research Institute of Highway Ministry of Transport, Component of flexible system for protecting highway slope (JT/T 528-2004). Beijing: China Communications Press, 2004.

[10] Standard and Metrology Research Institute of the Ministry of Railway, The flexible safety net for protection of slope along the line (TBT/T 3089-2004). Beijing: China Railway Publishing House, 2004.

[11] C. Zhang, "Fiber Bragg grating intelligent perimeter security method and key technology research," Ph.D. dissertation, Wuhan University of Technology, China, 2013.

[12] A. Zhang, S. Gao, G. Yan, and Y. Baiet, "Advances in optical fiber Bragg grating sensor technologies," Photonic Sensors, 2012, 2(1): $1-13$.

[13] C. Zhang, L. Wang, B. Lin, Y. Dai, and W. Gan, “A novel invasion algorithm for FBG perimeter security system," Journal of Optoelectronics-Laser, 2013, 24(6): 1138-1144.

[14] C. Zhang, L. Wang, B. Lin, Y. Dai, and W. Gan, "Identical FBG vibration sensor for perimeter security system," Semiconductor optoelectronics, 2013, 34(3): 516-520. 